the control of communicable disease. A recent example is the largest recorded food related outbreak of paratyphoid, which occurred in Birming ham early this year and was successfully dealt with under the present control of infection arrangements. Another example is the outbreak of legionnaires' disease in London which Dr Cunningham and her colleagues had to deal with. One shudders to think what would have happened if the government had accepted the Acheson recommendations when the report was published.

Control of infection has progressed since the major outbreaks of salmonella food poisoning at the Stanley Royd Hospital, Wakefield, and of legionnaires' disease in Stafford. Several models of good practice are now available in the provinces, including Birmingham. Health authorities in London would do well to adopt these practices, which emphasise the important role of local authorities in respect of communicable disease and the link with the medical officer for environmenta health in his role as proper officer. The models rely on the effective use of available resources. This is not the time to impose an unnecessary financia commitment on the National Health Service. Be sides, historical evidence suggests that the health service would not be able to cope with the demands of the organisation of the nationwide control of infection services outside the National Health Service. No other Western country has abandoned the system built on local authority medical officers of health for controlling infection. It is time that we returned to it.

S S BAKHSHI

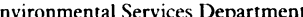

Birmingham B3 2EZ

1 Department of Health and Social Security. Public health in England. The report of the committee of inquiry into the future development of the public health function. London: HMSO, development of the public
1988. (Acheson report.)

\section{Flow properties of white blood cells}

We agree, albeit with some reservations, with the conclusions of Dr G B Nash and others in their paper about the abnormal flow properties of white blood cells in patients with severe ischaemia of the leg (18 June, p 1699).

Modern technology has not yet developed an instrument capable of monitoring the activation of white blood cells; thus, although an understanding of trapping, activation, and endothelial damage leading in turn to further trapping and activation will undoubtedly constitute the principal objectives of future studies, currently little of the whole phenomenon can be studied. What has been developed is a system of measuring the filterability of each individual leucocyte subpopulation (modified method of Lennie $e t a l^{1}$ ), which permits attention to be focused on the trapping stage of this vicious cycle. The preliminary results of our controlled dynamic study of patients with stage II peripheral vascular disease are interesting in this respect.

We monitored the rates of filtration of polymorphonuclear leucocytes, lymphocytes, and monocytes in control subjects and patients with peripheral vascular disease before and after treadmill exercise until the pain threshold was reached or for a maximum of five minutes. The mean values remained virtually unchanged in the controls, but the rigidity of the monocytes increased significantly in the patients. After 10 minutes' recovery in the controls and the return of the pressure index to baseline values in the patients another blood sample was taken for the same tests of filterability; the results showed that in the patients the monocytes' rate of filtration returned to basal values (table). These results confirm that even the earliest stages of ischaemia are directly linked to an
Mean $(S D)$ rates of filtration ${ }^{\star}$ of granulocytes, lymphocytes, and monocytes before and after treadmill exercise and after recovery in eight patients with peripheral vascular disease and eight matched controls

\begin{tabular}{|c|c|c|c|}
\hline & $\begin{array}{c}\text { Before } \\
\text { exercise }\end{array}$ & $\begin{array}{l}\text { After } \\
\text { exercise }\end{array}$ & $\begin{array}{l}\text { After } \\
\text { recovery }\end{array}$ \\
\hline \multicolumn{4}{|c|}{ Granulocytes } \\
\hline Controls & $4.00(0.71)$ & $4.02(0.67)$ & $4 \cdot 10(0.71)$ \\
\hline Patients & $4.12(0.71)$ & $4.23(0.55)$ & $4.15(0.71)$ \\
\hline \multicolumn{4}{|c|}{ Lymphocytes } \\
\hline Controls & $5.02(0.88)$ & $5 \cdot 30(1 \cdot 36)$ & $4.95(0.89)$ \\
\hline Patients & $5.13(0.97)$ & $5.55(1.32)$ & $5.40(1.31)$ \\
\hline \multicolumn{4}{|c|}{ Monocytes } \\
\hline Controls & $9.03(0.75)$ & $8.97(1.34)$ & $8.95(0.84)$ \\
\hline Patients & $9 \cdot 22(1.37)$ & $10 \cdot 30(1.51) \dagger$ & $9 \cdot 40(1 \cdot 16)$ \\
\hline
\end{tabular}

^Pressure ratio of cell suspension to buffer after six minutes' filtration. $t p \leqslant 0 \cdot 01$

impairment in the rheological properties of monocytes, which may because of their size and possible activation contribute to both the ischaemia and the pain.

We think that focusing attention on the rheological behaviour of individual leucocyte populations will lead to a better understanding of the first stage of the mechanism so well described by Dr Nash and others and eventually to a new, improved pharmacological approach to the treatment of vascular diseases.

GIOVANNI CIUFFETTI MICHELE MERCURI MARIA TERESA RIZZO

Istituto Il Clinica Medica Generale RITA LOMBARDINI

e Terapia Medica, 06100 Perugia, Italy

1 Lennie SE, Lowe GDO, Barbenel JC, Forbes CD, Foulds WS Filterability of white blood cell subpopulations, separated by an improved method. Clinical Hemorheology 1987;7:811-6.

\section{Deep vein thrombosis}

Mr John H Scurr and others (2 July, p 28) highlight the importance of prophylaxis against deep vein thrombosis in surgical patients. Subcutaneous sodium heparin given twice daily in conjunction with the use of graduated elastic compression stockings is the usual practice, but this stops when the patients go home.

For treating established deep vein thrombosis a recent innovation has been the use of calcium heparin given by deep subcutaneous injection instead of the more labour intensive and cumbersome intravenous infusion of sodium heparin. The benefit of using calcium heparin is that it is much easier to give, and it is favoured by the patients because they are not attached to a pump and can wash and dress as usual. Because of its long half life calcium heparin can be given 12 hourly at a dose of 250 units $/ \mathrm{kg}$. The kaolin clotting time should be assessed daily, and at least six hours should elapse from the last injection before blood is taken for assay so that the basal anticoagulan effect may be assessed. The dose can then be altered to maintain the kaolin clotting time at between one and a half and two times the control value

In view of the undoubted benefit of calcium heparin in the treatment of deep vein thrombosis I propose that it may be of benefit in patients who have been discharged home after an operation but who are not fully mobile. Calcium heparin could be given at a reduced dose of, say, 100 units $/ \mathrm{kg}$ as a once daily bolus injection given by the district nurse. This requires further investigation because it is not certain whether the prevention of deep vein thrombosis would be possible using such a regimen.

Wycombe General Hospital High Wycombe HP11 2T
1 Walker MG, Shaw JW, Thomson GJL, Cumming JGR, Lea TM. Subcutaneous calcium heparin versus intravenous sodium heparin in treatment of established acute deep vein thrombosis of the legs: a multicentre prospective randomised trial. BrMed F 1987;294:1189-92.

2 Connolly AAP. Calcium heparin in the treatment of venous thrombosis. MIMS Magazine (in press)

\section{Delayed communication between hospitals and general practitioners}

The problem of communication between hospitals and general practitioners has been raised again. Dr T M Penney (2 July, p 28) has identified delays in typing, posting, and delivering letters to general practitioners. Among the problems of lack of time and heavy workload is a lack of appreciation of the value of an accurate and timely discharge letter. Studies concentrate on the mechanics of communication rather than the education of junior doctors.

Time in hospital grand rounds and postgraduate meetings should be used for seminars to discuss the importance of discharge summaries. Seminars could include debate by general practitioners, consultants, and junior staff and presentation of cases in which lack of timely information has caused problems. Patients and relatives could also be invited to put forward their views on how important timely information is for the management of their problems. Increasing the motivation to provide accurate and timely discharge notes may achieve more than complex policies and expensive information technology. It is often the human factor which is most responsible for delays and problems.

VERNON HOCHULI

Maidstone Health Authority,

Maidstone ME20 7N

Dr T M Penney (2 July, p 28) discusses delayed communication between hospitals and general practitioners. The backlog of untyped reports was identified as a major factor in this problem and was primarily the result of inadequate secretarial services.

The article by Miss Susan Jeavons (2 July, p 53) highlighted the poor career prospects for clerical staff. The current terms and conditions of service for medical secretaries are woefully inadequate, and it is proving impossible to recruit staff capable of doing the job for the salaries on offer. Conditions of employment may be an additional factor. It is common for no holiday relief to be offered, so a further backlog accumulates and the workload becomes overwhelming. Consequently staff leave, and a further deterioration in the service follows, with worsening conditions for the loyal staff who remain.

In our hospital the secretarial budget is underspent by approximately $£ 60000$, yet 18 secretaria posts are vacant. Not surprisingly no suitable applicants apply when similar posts outside the National Health Service are advertised at an annual salary of approximately $£ 2000$ more. No formula is available to fill some of the posts at an increased salary, so we have the amazing paradox of an underspent budget and too few secretaries

The NHS enjoys immense loyalty from many of its staff that compensates, to some extent, for underfunding. We are now at the stage where even the most loyal are unable to continue to subsidise the NHS by tolerating their current terms of service, and this results in the shortcomings identified by Dr Penney. His article emphasises that an adequate secretarial service is not a luxury but an essential link between hospital consultation or admission and further care by the general practitioner. The Whitley Council should take note.

Royal Infirmary

Edinburgh EH3 9YW 